\title{
BMJ Open Associations of health literacy with risk factors for diabetic foot disease: a cross- sectional analysis of the Southern Tasmanian Health Literacy and Foot Ulcer Development in Diabetes Mellitus Study
}

\author{
Pamela Chen, ${ }^{1}$ Michele Callisaya, ${ }^{2}$ Karen Wills, ${ }^{3}$ Tim Greenaway, \\ Tania Winzenberg ${ }^{\oplus}$
}

To cite: Chen P, Callisaya M, Wills K, et al. Associations of health literacy with risk factors for diabetic foot disease: a cross-sectional analysis of the Southern Tasmanian Health Literacy and Foot UIcer Development in Diabetes Mellitus Study. BMJ Open 2019;9:e025349. doi:10.1136/ bmjopen-2018-025349

- Prepublication history and additional material for this paper are available online. To view these files, please visit the journal online (http://dx.doi. org/10.1136/bmjopen-2018025349).

Received 12 July 2018 Revised 19 June 2019 Accepted 20 June 2019
Check for updates

(C) Author(s) (or their employer(s)) 2019. Re-use permitted under CC BY-NC. No commercial re-use. See rights and permissions. Published by BMJ.

For numbered affiliations see end of article.

Correspondence to Professor Tania Winzenberg; Tania.Winzenberg@utas.edu.au

\section{ABSTRACT}

Objectives Poor health literacy $(\mathrm{HL})$ is associated with poorer health outcomes in diabetes but little is known about its effects on foot disease. This study was aimed to determine the associations between $\mathrm{HL}$ and diabetic foot disease.

Design This is a cross-sectional analysis of baseline data from a prospective study of foot disease.

Setting Attendees of the Royal Hobart Hospital's Diabetes outpatient clinics.

Participants 222 people with type 1 or type 2 diabetes aged $>40$ years and without a history of foot disease, psychotic disorders or dementia.

Measures Outcomes were peripheral neuropathy, peripheral arterial disease and foot deformity according to published guidelines. The exposure, $\mathrm{HL}$, was measured using the short form Test of Functional Health Literacy in Adults (S-TOFHLA) and the Health Literacy Questionnaire (HLQ). Covariates included demographic characteristics, medical history, psychological measures and foot care behaviour.

Results 0 222 participants, 204 had adequate HL. (Mean (SD) S-TOFHLA scores were 31.9 (6.7)), mean(SD) HLQ scores were 134.4 (18.4)). In univariable but not multivariable analyses, higher S-TOFHLA scores were associated with lower overall risk for foot disease (OR $0.96,95 \% \mathrm{Cl} 0.93$ to 0.99 ) and loss of protective sensation (OR $0.95,95 \% \mathrm{Cl} 0.91$ to 0.995 ).

Conclusions These data provide little support for clinically important impacts of $\mathrm{HL}$ on risk factors for diabetic foot disease. However, in the absence of longitudinal data, such effects cannot be ruled out. Longitudinal studies measuring incident foot disease are needed to properly judge the potential for interventions improving $\mathrm{HL}$ to reduce the incidence of diabetic foot disease.

\section{INTRODUCTION}

Diabetes mellitus is common and costly with an estimated 425 million adults globally being diagnosed with and a further 629 million at
Strengths and limitations of this study

- Health literacy may have an important role in diabetic foot disease prevention.

- This study is the first to objectively assess and measure the association between health literacy and risk factors for diabetic foot disease.

- Our study is unique as two measurements of health literacy were used, which provided a broader assessment of an individual's health literacy beyond functional health literacy.

- Limitations of this study potentially include limited generalisability as participants were recruited from only one tertiary hospital clinic, though participant characteristics were similar to another national study of people with diabetes.

risk of developing diabetes in $2025^{1}$. Conservative projections of financial costs are greater than for the five most costly cancers in the USA. ${ }^{2}$

One of the most expensive and debilitating complications of diabetes is diabetic foot disease, the lifetime risk of which is as high as $25 \% .^{3}$ In theory, diabetic foot disease is preventable. Fundamental to foot disease development is peripheral neuropathy from prolonged hyperglycaemia. ${ }^{3}$ Undetected, repetitive minor trauma to an insensate, deformed foot is often exacerbated by reduced healing capacity from peripheral arterial disease. The consequent chronic wound may be complicated by osteomyelitis, and ultimately can result in limb loss. Diabetic foot disease precedes up to $85 \%$ of amputations, ${ }^{3}$ and is the leading cause of non-trauma-related amputations worldwide. Early identification of risk factors such as 
peripheral neuropathy, peripheral arterial disease and foot deformity is crucial for the early implementation of mitigation strategies including education which can empower people with diabetes to practise good foot care behaviours. ${ }^{4}$

Health literacy is defined as 'the cognitive and social skills which determine the motivation and ability of individuals to gain access to, understand and use information in ways which promote and maintain good health' ${ }^{5}$ It broadly comprises three domains in order of increasing difficulty: basic or functional health literacy relates to basic skills in reading and writing health information, communicative health literacy includes advanced cognitive skills required to extract and apply health information to an individuals' circumstances and the most advanced critical health literacy pertains to critically analysing information and using it in decision making. ${ }^{6}$

Inadequate health literacy has been identified as a major barrier to self-care in people with diabetes. ${ }^{7}$ Health literacy is crucial to the self-management demands of diabetes, which include diet and lifestyle changes, blood glucose management as well as incorporating lifestyle changes to prevent complications of the disease. With respect to foot care, the need for regular foot inspections, knowledge of appropriate footwear selection as well as the importance of timely medical attention when necessary can be demanding, especially for individuals with poor health literacy. ${ }^{8}$

Health literacy influences an individuals' ability to navigate and use the health system, engage and interact with healthcare providers and their level of knowledge about health conditions. ${ }^{9}$ Current literature suggests that people with diabetes have poor health literacy, ${ }^{8}$ which could disadvantage them when engaging in diabetes management strategies. ${ }^{9}$ Existing research supports this, with established associations between poor health literacy and diabetic complications of retinopathy and cerebrovascular disease. ${ }^{10}$ However, little is known about its associations with diabetic foot disease. ${ }^{10}$ Therefore, this study was aimed to use baseline data of a longitudinal study, the Southern Tasmanian Health Literacy and Foot Ulcer Development in Diabetes (SHELLED) study to describe the level of functional and multidimensional health literacy among people with diabetes, and determine the associations between health literacy and risk factors for diabetic foot disease.

\section{METHODS}

This cross-sectional analysis is of baseline data from the SHELLED study, a 4-year longitudinal study aiming to determine the associations of health literacy with foot ulceration in people with diabetes.

\section{Subjects}

Between January 2015 and July 2016, consecutive patients aged $>40$ years old and with no history of foot ulceration, who attended the Royal Hobart Hospital (RHH)
Diabetes Centre's Outpatient Clinics were approached by investigator podiatrist (PC) or a study volunteer to participate in this study. The RHH Diabetes Centre is the only tertiary diabetes service in Southern Tasmania, and patients attending this service had established diabetes, diagnosed according to WHO criteria. ${ }^{11}$ Participants were excluded if they had a history of amputation, a diagnosis of peripheral neuropathy attributed to other causes other than diabetes, gestational diabetes, psychotic disorders, dementia or blindness. Those who provided informed consent to participate were then contacted within 2 weeks and requested to complete a questionnaire at home prior to attending an assessment at the Menzies Institute for Medical Research at the University of Tasmania.

\section{Measures}

All participants attended a $90 \mathrm{~min}$ individual appointment at the Menzies Institute for Medical Research at the University of Tasmania. During this time, they underwent a foot risk factor assessment for loss of protective sensation, peripheral arterial disease and foot deformity with a registered podiatrist (PC), and a study volunteer or staff member administered cognitive and health literacy assessments. All other measures were from the questionnaire filled by the participant prior to the appointment and checked at the appointment for appropriate completion.

\section{Outcome measures}

Loss of protective sensation was assessed using the $10 \mathrm{~g}$ Semmes-Weinstein Monofilament and a neurothesiometer. ${ }^{12}$ The $10 \mathrm{~g}$ monofilament was used at 10 sites bilaterally (plantar first, third and fifth toes and metatarsophalangeal joints (MPJ), medial and lateral plantar arch, plantar heel and dorsally in between the first and second toes). Large fibre neuropathy was tested using a calibrated neurothesiometer at the bony prominence of the first MPJ bilaterally. Participants were classified as having peripheral neuropathy if they were unable to detect the $10 \mathrm{~g}$ monofilament at any one site on either foot or had a vibration perception $>25 \mathrm{~V}^{12}$

To measure peripheral arterial disease, systolic blood pressures were measured using handheld Doppler (Hadeco Smartdop 45) and sphygmomanometer for dorsalis pedis, posterior tibial arteries and brachial arteries bilaterally. Ankle brachial index (ABI) was calculated for each side by dividing the highest pressure of either pedal vessel on each foot by the highest pressure in either brachial vessel as the numerator. ${ }^{13}$ Individuals were considered to have peripheral arterial disease if their ABI was $<0.9$ (indicative of arterial stenosis) or $>1.3$ (indicative of arterial calcification) on either side. ${ }^{13}$

Foot deformity was assessed using the six-point foot deformity score, with each of the following characteristics scored as 0 (absent) or 1 (present): small muscle wasting, Charcot foot, bony prominences, prominent metatarsal heads, hammer/claw toes and limited joint mobility. Significant foot deformity was deemed present if the total 
score was $>3$ (out of 6 ) on either foot. ${ }^{12}$ The foot deformity score is predictive of diabetic foot ulceration. ${ }^{14}$

Participants' overall level of risk for foot disease was classified according to Australian guidelines ${ }^{12}$ by the number of diabetic foot disease risk factors present (loss of protective sensation, peripheral arterial disease and foot deformity). Individuals with no risk factors were classified as low risk, with one risk factor as intermediate risk and with two or more risk factors as high risk.

\section{Exposure measures}

Health literacy was measured with two questionnaires. The short form Test of Functional Health Literacy in Adults (S-TOFHLA) was used as an established measure of functional health literacy. The Health Literacy Questionnaire (HLQ) was used as it assesses nine dimensions of health literacy and captures a broader representation of the constructs of health literacy.

The S-TOFHLA is a 36-item timed test of comprehension which uses a modified cloze procedure. Participants complete two passages, one from an upper gastrointestinal tract series about having an X-ray, and another from the 'patient rights and responsibilities' section of an American Medicaid application form. ${ }^{15}$ We advised participants verbally of Australian equivalents for two American terms, namely Medicaid (Medicare in Australia) and Temporary Assistance for Needy Family (Centrelink for Australia). The S-TOFHLA has excellent reliability (Cronbach's alpha $=0.98$ ) and good convergent validity with the Rapid Estimate of Adult Literacy in Medicine $(0.80) \cdot{ }^{15}{ }^{16} \mathrm{It}$ is scored out of 36 , with participants scoring $<17$ considered to have inadequate health literacy, those scoring between 17 and 22, marginal health literacy and those scoring $>22$ considered to have adequate health literacy.

The HLQ was developed in 2013 using a validity-driven approach. The HLQ consists of nine scales covering different dimensions of health literacy. ${ }^{17}$ The scales are (1) feeling understood and supported by healthcare professionals (four items), (2) having sufficient information to manage my health (four items), (3) actively managing my health (five items), (4) social support for health (five items), (5) appraisal of health information (five items), (6) ability to actively engage with healthcare providers (five items), (7) navigating the health system (five items), (8) ability to find good health information (five items) and (9) understanding health information well enough to know what to do (five items). Scales 1 to 5 are scored out of 4 (strongly disagree, disagree, agree, strongly agree), and scales 6 to 9 , which measure difficulty of health-related tasks to the individual, are scored out of 5 (cannot do or always difficult, usually difficult, sometimes difficult, usually easy and always easy). Individual scales of the HLQ have excellent reliability (composite reliability ranging between 0.77 and 0.89$).{ }^{17}$ The content of items of scales 8 and 9 were deemed by the authors of this paper to be most similar to functional health literacy as measured by the S-TOFHLA.

\section{Other covariates}

Demographic characteristics and medical history were assessed by questionnaire (age, sex, years of formal education and highest educational qualifications, employment status, source of income, annual household income bracket, smoking status, medical history including of diabetes (including type, age of diagnosis, monitoring of diabetes and insulin therapy)) .

A battery of psychological measures were also used. Descriptions on scoring, reliability and validity of these are available in table 1. Diabetes self-efficacy was assessed using the Australian version of the Diabetes Management Self-Efficacy Scale which measures the extent to which participants are confident they can perform a range of diabetes-related tasks such as managing blood glucose and foot care. ${ }^{18}$ Foot care self-efficacy was assessed using the Foot Care Confidence Scale, ${ }^{19}$ which measures the extent to which participants are confident of performing a range of foot care behaviours such as checking their feet or trimming their toenails. Diabetes knowledge was assessed using the diabetes knowledge questionnaire. ${ }^{20}$ Depression was assessed by the Patient Health Questionnaire-9 (PHQ-9), a depression screening tool with a sensitivity and specificity of $92 \%$ and $82 \%$, respectively, for the diagnosis of major depression according to DSM-IV criteria $^{21}$ and can be used to assess severity of depression symptoms. The Montreal Cognitive Assessment (MOCA) was administered during the appointment. ${ }^{22}$ This is a validated screening tool with scores $<26 / 30$ considered positive for mild cognitive impairment in people with diabetes. $^{22}$

Foot care behaviours were also assessed. There is no gold standard approach for this. ${ }^{23}$ We used the foot care behaviour scale (see table 1) as this 17-item questionnaire is a standardised questionnaire based on diabetic foot care guidelines ${ }^{192}$ that has been used previously ${ }^{24}$ including in an Australian setting ${ }^{25}$ to assess frequency of diabetic foot care behaviours.

\section{Statistics}

The sample size of 220 was estimated based on the number needed to detect associations of S-TOFHLA categories (adequate vs inadequate health literacy) with foot ulcer incidence over 4 years in the longitudinal study. Based on estimates by the Australian Bureau of Statistics, ${ }^{26}$ we projected that $60 \%$ of our study sample will have inadequate health literacy. Furthermore, based on worldwide reports of incidence of foot ulceration of between $2 \%$ and $5 \%$ in developed countries, ${ }^{1427}$ a sample of 220 would give power at $80 \%$ to be able to detect a $3.8 \%$ difference in incidence of foot ulceration between people with inadequate and adequate health literacy.

For this cross-sectional analysis, we estimated the prevalence of foot disease risk factors from published community findings of risk factor incidence. ${ }^{28}{ }^{29}$ With the sample size of 220 required for the longitudinal study, this cross-sectional analysis can detect a 2-point difference (mean effect size of 0.4) in S-TOFHLA scores 
Table 1 Description of psychological and behavioural questionnaires administered in the SHELLED study

\begin{tabular}{|c|c|c|c|c|}
\hline Questionnaire & $\begin{array}{l}\text { Number of } \\
\text { items }\end{array}$ & Scoring & Validity or reliability & Example questions \\
\hline $\begin{array}{l}\text { Diabetes Management } \\
\text { Self-Efficacy Scale }\end{array}$ & 20 & $\begin{array}{l}0-10 \text { per item, possible score } \\
\text { range 0-200. Low scores } \\
\text { indicate low confidence in self- } \\
\text { management of diabetes }\end{array}$ & $\begin{array}{l}\text { Cronbach's } \\
\text { alpha }=0.91^{18}\end{array}$ & $\begin{array}{l}\text { I am able to take my } \\
\text { medication as prescribed }\end{array}$ \\
\hline $\begin{array}{l}\text { Foot Care Confidence } \\
\text { Scale }\end{array}$ & 12 & $\begin{array}{l}1-5 \text { per item, possible score } \\
\text { range } 12-60 \text {. Low scores } \\
\text { indicate poor confidence in } \\
\text { caring for feet }\end{array}$ & $\begin{array}{l}\text { Cronbach's } \\
\text { alpha }=0.92^{19}\end{array}$ & I can protect my feet \\
\hline $\begin{array}{l}\text { Diabetes Knowledge } \\
\text { Questionnaire }\end{array}$ & $12-15^{*}$ & 1 for each correct answer & $\begin{array}{l}\text { Cronbach's } \\
\text { alpha }=0.73^{20}\end{array}$ & $\begin{array}{l}\text { What is the ideal range for } \\
\text { blood glucose (sugar) levels a } \\
\text { person with diabetes should } \\
\text { aim for? Select ONE answer } \\
\text { only } \\
2-6 \mathrm{mmol} / \mathrm{L} \\
7-13 \mathrm{mmol} / \mathrm{L} \\
4-8 \mathrm{mmol} / \mathrm{L} \\
4.5-15 \mathrm{mmol} / \mathrm{L} \\
\text { Unsure }\end{array}$ \\
\hline $\begin{array}{l}\text { Patient Health } \\
\text { Questionnaire-9 } \\
\text { (Depression) }\end{array}$ & 9 & $\begin{array}{l}0-3 \text { for each question, possible } \\
\text { score range } 0-27 . \text { High scores } \\
\text { indicate frequently experiencing } \\
\text { depressive symptoms }\end{array}$ & $\begin{array}{l}\text { Sensitivity: } 92 \% \\
\text { Specificity: } 82 \%{ }^{21}\end{array}$ & $\begin{array}{l}\text { Feeling down, depressed or } \\
\text { hopeless }\end{array}$ \\
\hline Diabetes Distress scale & 17 & $\begin{array}{l}\text { 1-6 for each item, high scores } \\
\text { indicate aspects of distressed } \\
\text { behaviours are a serious } \\
\text { problem }\end{array}$ & $\begin{array}{l}\text { Cronbach's alpha } \\
=0.93^{50}\end{array}$ & $\begin{array}{l}\text { Feeling that diabetes is taking } \\
\text { up too much of my mental } \\
\text { and physical energy every } \\
\text { day }\end{array}$ \\
\hline $\begin{array}{l}\text { Montreal Cognitive } \\
\text { Assessment }\end{array}$ & 30 & $\begin{array}{l}0-30 . \text { Scores }<26 / 30 \text { indicate } \\
\text { mild cognitive impairment }{ }^{22}\end{array}$ & $\begin{array}{l}\text { Internal consistency } \\
0.83^{22}\end{array}$ & $\begin{array}{l}\text { Clock face drawing, delayed } \\
\text { recall etc. }\end{array}$ \\
\hline
\end{tabular}

*Twelve items if diabetes managed without medication, 14 items if diabetes managed with medication and 15 items for people living with type 1 diabetes.

SHELLED, Southern Tasmanian Health Literacy and Foot Ulcer Development in Diabetes.

between overall foot risk groups. The minimum clinically important difference in S-TOFHLA scores is not known; however, this detectable difference is small relative to the difference in 10 points across the three categories of health literacy (inadequate, marginal, adequate). Furthermore, a 5-point increase in S-TOFHLA score is associated with a $0.1 \%$ greater $\mathrm{HbAlc}$; thus, the ability to detect a 2-point change is conservative and minimises risk of type II error. ${ }^{30}$

There were four outcome measures-each individual risk factor and the overall risk for foot disease (low, intermediate and high). There were also three exposure measures-the continuous S-TOFHLA score, continuous HLQ score and category of HLQ from cluster analysis.
The continuous HLQ score was calculated by rescaling participants' scores on scales out of 4 to 5 to enable equal weighting of all items then summing the scores across all scales. Clusters of HLQ were determined using agglomerative cluster analysis with Ward's linkage method (minimal increase in sum of squares). ${ }^{31}$ The number of clusters was chosen based on the distribution of mean scores of all covariates and approximated groups of participants with lowest, intermediate and highest levels of health literacy scored on the HLQ.

Logistic regression was used to estimate the association of health literacy with the presence of individual risk factors. Adjacent categories ordinal logistic regression models were used to estimate the association of health 


\begin{tabular}{|c|c|c|c|c|c|}
\hline Variable & $\mathbf{n}$ & Overall sample & Low risk $(n=127)$ & Medium risk $(n=81)$ & High risk $(n=14)$ \\
\hline Age (years) & 222 & $60.5(10.7)$ & $59.2(9.8)$ & $63.4(11.1)$ & $68.1(11.6)$ \\
\hline Female, n (\%) & 222 & $92(41.4)$ & $67(52.8)$ & 24 (29.6) & $1(7.1)$ \\
\hline BMI $\left(\mathrm{kg} / \mathrm{m}^{2}\right)$ & 221 & $33.6(8.1)$ & $33.03(8.6)$ & $34.4(7.0)$ & $33.1(9.3)$ \\
\hline Years of formal education & 220 & $11.3(3.3)$ & $11.4(3.3)$ & $11.0(3.5)$ & $11.6(2.8)$ \\
\hline \multicolumn{6}{|l|}{ Household income, n(\%) } \\
\hline$<\$ 49999$ & 222 & $148(66.7)$ & $82(64.6)$ & 55 (67.9) & $11(78.6)$ \\
\hline$\$ 50$ 000-\$99999 & & $27(12.2)$ & $16(12.6)$ & $11(13.6)$ & $0(0)$ \\
\hline$>\$ 100000$ & & $18(8.1)$ & $12(9.4)$ & $5(6.2)$ & $1(7.1)$ \\
\hline Rather not say & & $29(13.1)$ & $17(13.4)$ & $10(12.3)$ & $2(14.3)$ \\
\hline \multicolumn{6}{|l|}{ Diabetes history } \\
\hline Duration in years & 222 & $18.0(13.4)$ & $16.2(13.2)$ & $20.7(13.9)$ & $18.8(9.6)$ \\
\hline Insulin therapy, n(\%) & 222 & $173(77.9)$ & $93(73.2)$ & $66(81.4)$ & $14(100)$ \\
\hline Current smoker, n(\%) & 222 & 33 (14.9) & $23(18.1)$ & $10(12.3)$ & $0(0)$ \\
\hline Current or ex-smoker, n(\%) & 222 & $129(58.1)$ & $73(57.5)$ & $49(60.5)$ & $7(50)$ \\
\hline S-TOFHLA score & 222 & $31.9(6.7)$ & $33.0(5.3)$ & $30.8(5.1)$ & $29.0(8.3)$ \\
\hline S-TOFHLA score* & 222 & $34(32-36)$ & $35(33-36)$ & $20(17-21)$ & $9(5.5-11.25)$ \\
\hline HLQ score & 222 & $134.4(18.4)$ & $135.2(18.2)$ & $135.7(18.2)$ & $127.1(21.1)$ \\
\hline Foot Care Confidence Scale & 222 & $49.4(9.7)$ & $50.4(9.6)$ & $48.9(9.5)$ & $43.3(10.4)$ \\
\hline PHQ-9 & 221 & $7.2(6.3)$ & $7.5(6.5)$ & $7.1(6.1)$ & $5.1(5.2)$ \\
\hline Diabetes distress & 221 & $1.7(0.8)$ & $1.8(0.8)$ & $1.7(0.7)$ & $1.9(1.1)$ \\
\hline MOCA & 222 & $25.7(3.5)$ & $26.2(3.1)$ & $25.2(3.8)$ & $24.2(3.8)$ \\
\hline DMSES & 222 & $9.5(1.7)$ & $9.5(1.7)$ & $9.7(1.6)$ & $8.5(2.2)$ \\
\hline Foot care behaviour & 222 & $0.7(0.2)$ & $0.7(0.2)$ & $0.7(0.2)$ & $0.8(0.2)$ \\
\hline Diabetes knowledge & 222 & $73.2(19.0)$ & $75.0(19.3)$ & 70.8 (19.0) & $71.5(14.5)$ \\
\hline
\end{tabular}

*Additional data for S-TOFHLA are presented as Median (IQR).

Data presented as mean(SD) unless otherwise stated;

Diabetes Distress scored out of 6.

Diabetes Knowledge Questionnaire scored out of 100.

Foot care behaviour scored out of 2 .

BMI, body mass index; DMSES, Diabetes Management Self-Efficacy Scale (scored out of 30); HLQ, Health Literacy Questionnaire (scored out of 176) ; MOCA, Montreal Cognitive Assessment (maximum score 30); PHQ-9, Patient Health Questionnaire (nine items, maximum score 27); SHELLED, Southern Tasmanian Health Literacy and Foot Ulcer Development in Diabetes; S-TOFHLA, short form Test of Functional Health Literacy in Adults (scored out of 36).

literacy with overall risk of foot disease. The odds ratios estimated for a unit increase in health literacy represent the odds of moving from any outcome category to an adjacent (higher) risk category. We ensured all assumptions for regressions were met, with only diabetes and foot care self-efficacy having a statistically significant correlation. We selected potential confounders based on clinical and biological plausibility of an association of a factor with both the outcome and exposure of interest. These were included in the model if their inclusion caused a change of $>10 \%$ in the estimated coefficient for the effect of the exposure. $^{32}$

As the number of individuals with missing data for relevant variables was very small (one to two people, see table 2), those with missing data required for a given regression analysis were excluded.
All analyses were done in R V.1.0.44 ( $\mathrm{R}$ Core Team, 2018) using the packages VGAM ${ }^{33}$ and cluster ${ }^{34}$.

\section{Patient and public involvement}

No patients were involved in setting the research question or the outcome measures, nor were they involved in developing plans for recruitment, design or implementation of the study. No patients were asked to advise on interpretation or writing up of results.

\section{RESULTS}

\section{Participant characteristics}

Four hundred and eleven people who were approached indicated an initial interest in participating in the study, of whom 222 ultimately consented to participate. The most 
common reason for declining was lack of time, or of difficulty with transport to attend an assessment. Of the 222 participants, one individual was wheelchair-bound and unable to provide height and weight measures; another declined to complete the PHQ and diabetes distress measures, citing diagnosis and treatment for depression.

Characteristics of the whole study sample and of the participants by their overall risk of diabetic foot disease are given in table 2. Data on characteristics of those who chose not to participate are not available. Participants were predominantly $(58.6 \%)$ male, with a mean age of 60.5 (SD 10.7) years. The average BMI was 33.6 (SD 8.1) $\mathrm{kg} / \mathrm{m}^{2}$. The duration of diabetes was an average of 18.0 years and $77.9 \%$ of participants were insulin-treated. Thirty-three $(14.9 \%)$ participants were current smokers, and an additional $96(43.2 \%)$ were regular smokers in the past. Mean(SD) MOCA score was 25.7 (3.5) (range 0-30), with 88 participants considered to have mild cognitive impairment. ${ }^{22}$ Mean(SD) diabetes knowledge score was $73.2(19.0)(/ 100)$.

A majority $(n=127,57.2 \%)$ of participants had no risk factors for foot disease, $81(36.5 \%)$ were at intermediate risk with one risk factor and $14(6.3 \%)$ were at high risk of foot disease with $>1$ risk factor present. Of the total sample, $12(5.4 \%)$ had inadequate, $6(2.7 \%)$ marginal and $204(91.9) \%$ adequate functional health literacy according to S-TOFHLA cut-offs.

Participants at high risk of foot disease were older, had a higher proportion of people in the lowest income group, had lower S-TOFHLA and HLQ scores and poorer diabetes and foot care self-efficacy. Scores for cognition, diabetes knowledge, BMI, as well as years of formal education were similar across all three categories. Participants at medium and high risk for foot disease reported a longer duration of diabetes compared with those at low risk of foot disease. Furthermore, all participants at high risk of foot disease were undergoing insulin therapy, compared with only $73.2 \%$ of those at low risk and $81.4 \%$ of those at medium risk of foot disease.

\section{Associations of health literacy with risk factors for and overall risk of diabetic foot disease}

Table 3 shows odds ratios (ORs), estimated for a unit increase in health literacy, for having risk factors for foot disease. Each unit increase in S-TOFHLA scores was associated with $4 \%$ lower odds of being in a higher risk category for foot disease (OR $0.96,95 \%$ CI 0.93 to 0.99 ) in univariable analyses. However, this association did not persist after adjusting for age, sex and other covariates. Although the direction of effect was similar for total HLQ score and for HLQ clusters, there were no statistically significant associations with these HLQ measures.

For the individual risk factors (table 3, online supplementary tables S1, S2 and S3), in univariable analyses S-TOFHLA and HLQ score but not HLQ clusters were significantly associated with loss of protective sensation, but again these associations did not persist after adjustment for age and sex, or other covariates. There were no associations between any measure of health literacy and peripheral arterial disease or foot deformity.

Of individual HLQ scales, scales 8 (ability to find good health information) and 9 (understanding health information well enough to know what to do) were associated with being in a higher overall risk category for foot disease and loss of protective sensation in univariable analyses only (online supplementary tables S4). For overall risk for foot disease, the odds ratios were 0.93 (95\% CI 0.88 to 0.99 ) and 0.93 (95\% CI 0.87 to 0.99 ) for scales 8 and 9 , respectively, and for loss of protective sensation, these were 0.90 (95\% CI 0.82 to 1.01 ) and 0.84 (95\% CI 0.79 to $0.99)$. There were no other statistically significant associations between any HLQ subscale and any outcome.

\section{DISCUSSION}

This novel study is the first to examine the relationship between health literacy and the number of risk factors for diabetic foot disease, the first to examine relationships with peripheral neuropathy using objective clinical measures of this risk factor and the first to assess associations with peripheral vascular disease in a broad diabetic population. There was a small reduction in the odds of being in a higher risk category (ie, having a greater number of risk factors) for diabetic foot disease per unit increase in S-TOFHLA score and per unit increase in HLQ subscale 8 and 9 scores in univariable analysis. Similarly, there was a small reduction in the odds of having loss of protective sensation with higher S-TOFHLA and HLQ total scores, and a more substantial decrease in odds (approaching $70 \%$ ) in participants in the high versus low HLQ cluster in univariable analysis. However, as these effects did not persist after adjusting for potential confounders, overall, there is little evidence to support there being clinically important impacts of health literacy on the presence of risk factors for diabetic foot disease. This lack of effect may reflect the complex, multifactorial nature of diabetic foot disease development and the different aetiologies of different foot disease risk factors. However, the results are insufficient to as yet judge the potential for interventions that improve or overcome low health literacy to reduce the incidence of diabetic foot disease.

Few studies have examined the links between health literacy and individual foot disease risk factors. Overall foot disease risk level and the individual risk factors of peripheral neuropathy were significantly associated with S-TOFHLA scores and scores of the subscales 8 and 9 of the HLQ but this appears to have been due to confounding by age and gender. This similarity of pattern between these HLQ subscales and S-TOFHLA is unsurprising as these most closely approximate measures of functional health literacy. Current evidence pertaining to the influence of each domain of health literacy with self-management or clinical outcomes is conflicting ${ }^{35}{ }^{36}$; however, for risk factors for diabetic foot disease, our findings suggest that functional health literacy may be a more important domain. Further research is required to 


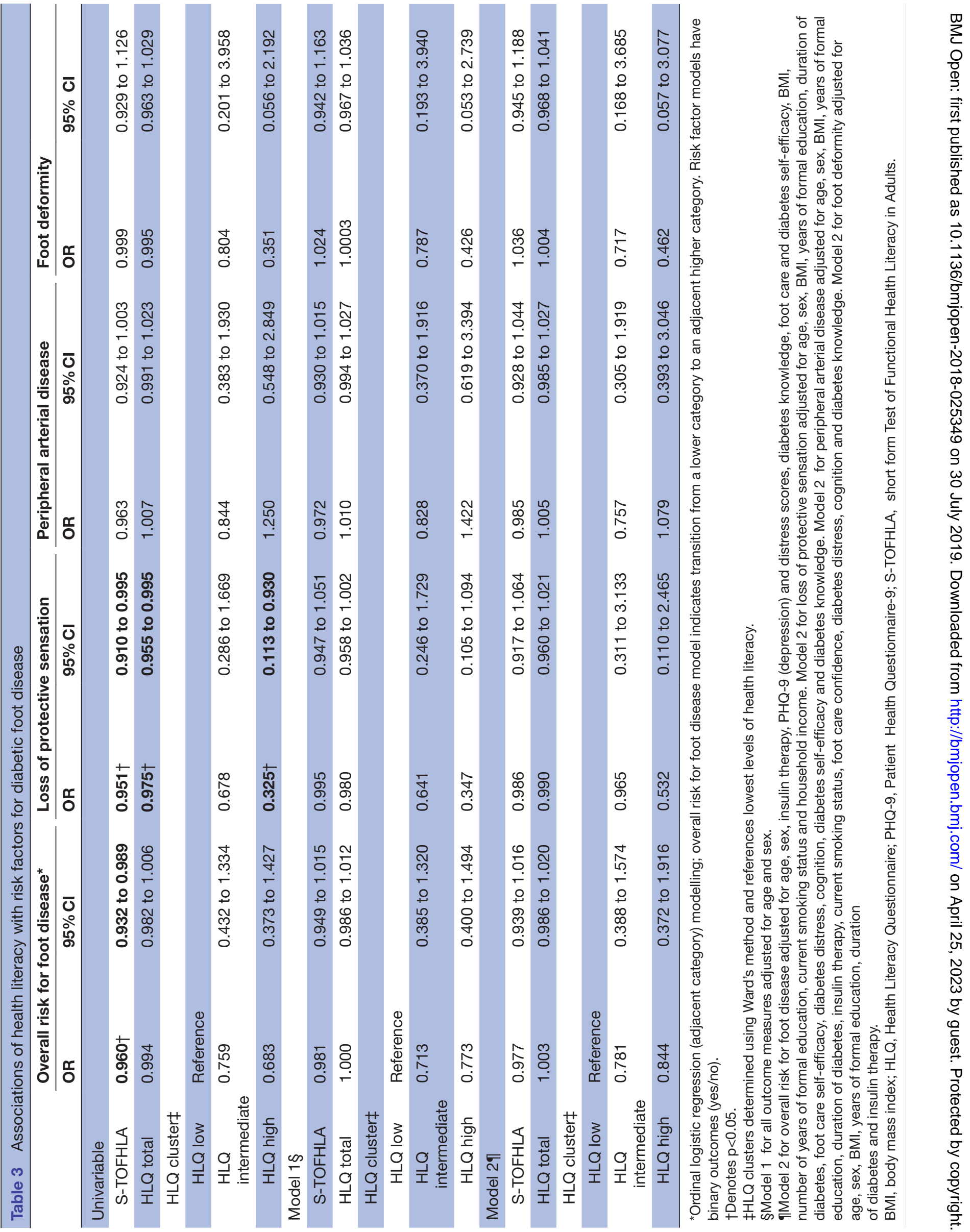


ascertain definitively if this is the most important aspect of health literacy in regard to foot disease prevention and management.

The lack of even univariable associations between health literacy and foot deformity and peripheral arterial disease may reflect the different mechanisms and aetiologies of these two risk factors. We postulate that the relationship between health literacy and presence of risk factors for diabetic foot disease may be mediated by glycaemic control. Low levels of health literacy are associated with poorer glycaemic control, ${ }^{1037}$ which is a predominant aetiology of peripheral neuropathy in people with diabetes. By contrast, peripheral arterial disease (being macrovascular in nature) has a multifactorial aetiology of which diabetes is a component. Similarly, foot deformity has several aetiologies, most of which are biomechanical and unrelated to systemic conditions such as diabetes and so may be least attributable to diabetes management and thus health literacy.

Foot disease risk factors are only intermediate outcomes and proxy measures for the more important clinical outcome of diabetic foot disease. To our knowledge, only three studies have reported on health literacy and diabetic foot disease outcomes of ulceration, ${ }^{38}$ amputation $^{7}$ and foot ulcer size and duration. ${ }^{39}$ In 408 patients with diabetes mellitus from primary care clinics, the odds of sustaining lower extremity amputation were nearly 2.5 times higher in patients with inadequate versus adequate health literacy, though this was not a statistically significant effect (OR $2.48,95 \%$ CI 0.78 to 8.34 ). ${ }^{7}$ In another primary care study of 1002 people with diabetes who were asked to report neuropathic symptoms and healthcare provider diagnosis of diabetes-related ulcers or sores on the leg or foot, there were no statistically significant associations between health literacy level and foot/leg problems (OR $0.52,95 \%$ CI 0.24 to 1.16 for inadequate health literacy and OR $1.39,95 \%$ CI 0.47 to 4.12 for marginal health literacy). ${ }^{38}$ We performed a meta-analysis pooling all available data and found a non-statistically significant, but potentially important clinically doubling of the odds of foot disease among people with inadequate compared with adequate health literacy (OR 1.99, 95\% CI 0.83 to 4.78). ${ }^{40}$ With only three studies available, the effect of health literacy on diabetic foot disease cannot be ruled out, and longitudinal studies will provide further important evidence on this topic.

Our findings alone are insufficient to judge whether it is justified to proceeding to further research such as randomised control trials on health literacy interventions to improve diabetic foot disease. At face value, our results would suggest not, but a recent systematic review suggested that significant $\mathrm{HbAlc}$ reductions were achieved with educational strategies which accommodated patients with low health literacy. ${ }^{41}$ It is also well established that tight glycaemic control with target HbAlc levels of $7 \%(53 \mathrm{mmol} / \mathrm{mol})$ greatly reduces risk of microvascular complications among people with diabetes. ${ }^{43}$ This makes obtaining longitudinal data on foot ulcer outcomes even more critical to guide future research directions.

Strengths of our study include its sample size being sufficient to detect small differences in health literacy across risk groups; utilisation of different measures to assess functional and multidimensional aspects of health literacy and our use of a range of validated patient-reported outcome measures to measure potential confounders. Nonetheless, our study has several limitations. Being cross-sectional in nature, our data prohibit attributing causation between health literacy and diabetic foot disease risk factors. Also, we were able to assess only associations with the overall risk for diabetic foot disease and its risk factors-longitudinal data with foot ulcer outcomes are essential to properly assess the potential for health literacy levels to impact on diabetic foot disease. The fact it was conducted at one tertiary hospital outpatient clinic in Hobart and the response rate of $54 \%$ could have limited generalisability to the wider population of people with diabetes. However, this does not seem to be the case. Our participants' characteristics were not dissimilar to those from centre of excellence/tertiary diabetes treatment centres in a national audit of diabetes centres, particularly given that the Australian National Diabetes Audit (ANDA) included people with gestational diabetes and people with a history of ulceration, which our sample did not. For example, body mass index and percentage treated with insulin were $33.6 \mathrm{vs} 31.3 \mathrm{~kg} / \mathrm{m}^{2}$ and $77.9 \%$ vs $72.2 \%$ in our sample and ANDA, respectively. ${ }^{44}$ The mean S-TOFHLA scores from our population was high (31.9), possibly attributable to the high levels of formal education reported ( $>11$ years). Although this is similar to other Australian-based health literacy studies, ${ }^{45}{ }^{46}$ we had initially projected having up to $60 \%$ of our population being assessed as having inadequate health literacy, which was based on the national survey. ${ }^{26}$ It may be that there is a threshold below which low health literacy has more substantial impacts on health outcomes, and we had insufficient participants below such a threshold to detect effects. There are no validated tools for foot deformity, but we used the recommended tool, being the 'six point foot deformity score' in our study. ${ }^{12}$ However, it could be criticised for requiring a score of 3 or more to be considered positive, when a single deformity could be clinically significant in contributing to foot ulcer development-individual aspects of foot deformity such as rigid or retracted lesser toes, hallux rigidus/limitus or abductovalgus deformities have been previously associated with foot ulceration. ${ }^{47}$ Finally, while we did not have public involvement in our study, the importance of health literacy for diabetes care is highlighted in the Australian National Diabetes Strategy 2016-2020 ${ }^{48}$, which was formulated after extensive public consultation, supporting the relevance of our study to people with diabetes.

In conclusion, foot disease remains one of the most costly and debilitating outcomes of diabetes, with a $40 \%$ greater 10-year mortality compared with those with diabetes alone. ${ }^{49}$ Our study, which is the first to examine 
the relationships between health literacy and foot disease and its risk factors using objective measurements, only showed associations of health literacy with risk factors for diabetic foot disease in univariable analyses. This suggests that focusing on health literacy alone may not be effective for reducing foot ulcer risk factors, but as cross-sectional evidence is weak, longitudinal or interventional studies are crucial to be able to attribute causation and to improve targeted diabetic foot care education, to ultimately improve diabetic foot disease prevention.

\section{Author affiliations}

${ }^{1}$ Faculty of Health, University of Tasmania, Hobart, Tasmania, Australia

${ }^{2}$ Academic Unit, Central Clinical School, Monash University, Melbourne, Victoria, Australia

${ }^{3}$ Respiratory Research Group, Menzies Research Institute, Hobart, Tasmania, Australia

${ }^{4}$ Menzies Research Institute Tasmania, University of Tasmania, Hobart, Tasmania, Australia

Acknowledgements The authors sincerely thank volunteers Dale Pitt and Deb Simmons, as well as staff Jill Finch and Trish Lewis for assisting with administration of questionnaires and data collection for the study.

Contributors $\mathrm{PC}$ was involved in recruitment and assessment procedures. All five authors (PC, MC, KW, TG and TW) made substantial contributions to the study design, analysis and interpretation of data, and critical revision of the paper for publication. All authors have read and approved the final manuscript.

Funding This was supported by the Australian Podiatry Education and Research Fund (grant number CNT05006)

Competing interests None declared.

Patient consent for publication Not required.

Ethics approval The study was approved by the Human Research Ethics Committee (Tasmania) Network (reference H0014284).

Provenance and peer review Not commissioned; externally peer reviewed.

Data sharing statement № additional data are available.

Open access This is an open access article distributed in accordance with the Creative Commons Attribution Non Commercial (CC BY-NC 4.0) license, which permits others to distribute, remix, adapt, build upon this work non-commercially, and license their derivative works on different terms, provided the original work is properly cited, appropriate credit is given, any changes made indicated, and the use is non-commercial. See: http://creativecommons.org/licenses/by-nc/4.0/.

\section{REFERENCES}

1. International Diabetes Federation (IDF) Diabetes Atlas. 8th ed. Belgium: BrusselsInternational Diabetes Federation, 2017.

2. Barshes NR, Sigireddi M, Wrobel JS, et al. The system of care for the diabetic foot: objectives, outcomes, and opportunities. Diabet Foot Ankle 2013;4:21847.

3. Singh N, Armstrong DG, Lipsky BA. Preventing foot ulcers in patients with diabetes. JAMA 2005;293:217-28.

4. Dorresteign JA, Kreigsman DM, Assendelft WJ, et al. Patient education for preventing diabetic foot ulceration. Cochrane Database Syst Rev 2012

5. Nutbeam D. Health promotion glossary. Health Promot Int 1998;13:349-64.

6. Nutbeam D. Health literacy as a public health goal: a challenge for contemporary health education and communication strategies into the 21st century. Health Promot Int 2000:15:259-67.

7. Schillinger D, Grumbach K, Piette J, et al. Association of health literacy with diabetes outcomes. JAMA 2002;288:475-82.

8. Williams MV, Baker DW, Parker RM, et al. Relationship of functional health literacy to patients' knowledge of their chronic disease. A study of patients with hypertension and diabetes. Arch Intern Med 1998;158:166-72.

9. Paasche-Orlow MK, Wolf MS. The causal pathways linking health literacy to health outcomes. Am J Health Behav 2007;31 Suppl 1(Suppl 1):19-26.
10. Dewalt DA, Berkman ND, Sheridan S, et al. Literacy and health outcomes: a systematic review of the literature. J Gen Intern Med 2004;19:1228-39. 1228-39.

11 Definition and Diagnosis of Diabetes Mellitus and Intermediate Hyperglycemia. Geneva, Switzerland, 2006.

12. NHMRC. National Evidence-Based Guideline on Prevention, Identification and Management of Foot Complications in Diabetes (Part of the Guidelines on Management of Type 2 Diabetes). Melbourne, Australia: National Health and Medical Research Council, 2011.

13. Ferket BS, Spronk S, Colkesen EB, et al. Systematic review of guidelines on peripheral artery disease screening. Am J Med 2012;125:198-208.

14. Abbott CA, Carrington $\mathrm{AL}$, Ashe $\mathrm{H}$, et al. The North-West Diabetes Foot Care Study: incidence of, and risk factors for, new diabetic foot ulceration in a community-based patient cohort. Diabet Med 2002;19:377-84.

15. Baker DW, Williams MV, Parker RM, et al. Development of a brief test to measure functional health literacy. Patient Educ Couns 1999;38:33-42.

16. Al Sayah F, Williams B, Johnson JA. Measuring health literacy in individuals with diabetes: a systematic review and evaluation of available measures. Health Educ Behav 2013;40.

17. Osborne RH, Batterham RW, Elsworth GR, et al. The grounded psychometric development and initial validation of the Health Literacy Questionnaire (HLQ). BMC Public Health 2013;13:658-76.

18. McDowell J, Courtney $\mathrm{M}$, Edwards $\mathrm{H}$, et al. Validation of the Australian/English version of the Diabetes Management Self-Efficacy Scale. Int J Nurs Pract 2005;11:177-84

19. Sloan HL. Developing and testing of the Foot Care Confidence Scale. J Nurs Meas 2002;10:207-18.

20. Eigenmann CA, Skinner T, Colagiuri R. Development and validation of a diabetes knowledge questionnaire. Practical Diabetes International 2011;28:166-70.

21. Gilbody S, Richards D, Brealey S, et al. Screening for depression in medical settings with the Patient Health Questionnaire (PHQ): a diagnostic meta-analysis. J Gen Intern Med 2007;22:1596-602.

22. Nasreddine ZS, Phillips NA, Bédirian V, et al. The Montreal Cognitive Assessment, MoCA: a brief screening tool for mild cognitive impairment. J Am Geriatr Soc 2005;53:695-9.

23. Bonner T, Foster M, Spears-Lanoix E. Type 2 diabetes-related foot care knowledge and foot self-care practice interventions in the United States: a systematic review of the literature. Diabet Foot Ankle 2016;7:29758.

24. Vileikyte L, Gonzalez JS, Leventhal H, et al. Patient Interpretation of Neuropathy (PIN) questionnaire: an instrument for assessment of cognitive and emotional factors associated with foot self-care. Diabetes Care 2006;29:2617-24.

25. Perrin BM, Swerissen H, Payne C. The association between footcare self efficacy beliefs and actual foot-care behaviour in people with peripheral neuropathy: a cross-sectional study. J Foot Ankle Res 2009;2:3.

26. ABS. Health Literacy, Australia. Canberra, Australia: Australian Bureau of Statistics, 2008.

27. Ramsey SD, Newton K, Blough D, et al. Incidence, outcomes, and cost of foot ulcers in patients with diabetes. Diabetes Care 1999;22:382-7.

28. Abbott CA, Vileikyte L, Williamson S, et al. Multicenter study of the incidence of and predictive risk factors for diabetic neuropathic foot ulceration. Diabetes Care 1998;21:1071-5.

29. Tapp RJ, Shaw JE, de Courten MP, et al. Foot complications in Type 2 diabetes: an Australian population-based study. Diabet Med 2003;20:105-13.

30. Morris NS, Maclean CD, Littenberg B. Change in health literacy over 2 years in older adults with diabetes. Diabetes Educ 2013;39:638-46.

31. Batterham RW, Buchbinder R, Beauchamp A, et al. The OPtimising HEalth LIterAcy (Ophelia) process: study protocol for using health literacy profiling and community engagement to create and implement health reform. BMC Public Health 2014;14:694.

32. Hosmer DW, Lemeshow S. Applied Logistic Regression. 2 ed: John Wiley \& Sons, Inc, 2005

33. Yee TW. The VGAM Package for Categorical Data Analysis. J Stat Softw 2010;32:1-34.

34. Maechler M, Rosseeuw P, Struyf A, et al. cluster: Cluster Analysis Basics and Extensions. R Package version 2017;206.

35. Heijmans M, Waverijn G, Rademakers J, et al. Functional, communicative and critical health literacy of chronic disease patients and their importance for self-management. Patient Educ Couns 2015;98:41-8.

36. Inoue M, Takahashi M, Kai I. Impact of communicative and critical health literacy on understanding of diabetes care and self-efficacy 
in diabetes management: a cross-sectional study of primary care in Japan. BMC Fam Pract 2013;14:40.

37. Bains SS, Egede LE. Associations between health literacy, diabetes knowledge, self-care behaviors, and glycemic control in a low income population with type 2 diabetes. Diabetes Technol Ther 2011;13:335-41.

38. Morris NS, MacLean CD, Littenberg B. Literacy and health outcomes: a cross-sectional study in 1002 adults with diabetes. BMC Fam Pract 2006;7:49.

39 Margolis DJ, Hampton M, Hoffstad O, et al. Health literacy and diabetic foot ulcer healing. Wound Repair Regen 2015;23:299-301.

40. Chen P, Elmer S, Callisaya M, et al. The associations of health literacy with diabetic foot outcomes - a Systematic Review and meta-analysis. Diabetic medicine: a journal of the British Diabetic Association 2018 (Accepted 26 Mar 2018).

41. Kim SH, Lee A. Health-Literacy-Sensitive Diabetes Self-Management Interventions: A Systematic Review and Meta-Analysis. Worldviews Evid Based Nurs 2016;13:324-33.

42. Intensive blood-glucose control with sulphonylureas or insulin compared with conventional treatment and risk of complications in patients with type 2 diabetes (UKPDS 33). UK Prospective Diabetes Study (UKPDS) Group. Lancet 1998;352:837-53.
43 Dekker RG, Qin C, Ho BS, et al. The effect of cumulative glycemic burden on the incidence of diabetic foot disease. J Orthop Surg Res 2016;11:143.

44 Australian National Diabetes Audit - Australian Quality Clinical Audit. Australia: National Association of Diabetes Centres, 2017.292.

45. Barber MN, Staples M, Osborne RH, et al. Up to a quarter of the Australian population may have suboptimal health literacy depending upon the measurement tool: results from a population-based survey. Health Promot Int 2009;24:252-61.

46. Buchbinder R, Hall S, Youd JM. Functional health literacy of patients with rheumatoid arthritis attending a community-based rheumatology practice. J Rheumatol 2006;33:879-86.

47. Monteiro-Soares M, Boyko EJ, Ribeiro J, et al. Predictive factors for diabetic foot ulceration: a systematic review. Diabetes Metab Res Rev 2012;28:574-600.

48 Australian National Diabetes Strategy 2016-2020. Health Do, Ed. Canberra, ACT, Australia, 2015.

49. Iversen MM, Tell GS, Riise T, et al. History of foot ulcer increases mortality among individuals with diabetes: ten-year follow-up of the Nord-Trøndelag Health Study, Norway. Diabetes Care 2009;32:2193-9.

50. Polonsky WH, Fisher L, Earles J, et al. Assessing psychosocial distress in diabetes: development of the diabetes distress scale. Diabetes Care 2005;28:626-31. 